Check for updates

Cite this: RSC Adv., 2018, 8, 41818

Received 26th August 2018

Accepted 4th December 2018

DOI: $10.1039 / \mathrm{c} 8 \mathrm{ra07116k}$

rsc.li/rsc-advances

\section{Facile synthesis of novel calcium silicate hydrated- nylon 6/66 nanocomposites by solution mixing method}

\author{
S. Estrada-Flores, (D) a A. Martínez-Luévanos, (D) *a P. Bartolo-Pérez, ${ }^{b}$ L. A. García- \\ Cerda, $^{c}$ T. E. Flores-Guia $\mathbb{D D}^{a}$ and E. N. Aguilera-González ${ }^{a}$
}

In this article a facile and green procedure for the synthesis of novel calcium silicate hydrated-nylon 6/66 nanocomposites is proposed. Calcium silicate hydrate (CSH) was synthesized by a hydrolysis technique assisted by ultrasound and using sodium dodecyl sulphate (SDS) as surfactant. CSH-nylon 6/66 nanocomposites were obtained by a solution mixing method at CSH loadings of 2.5, 25, 50 and 75 weight percent (samples CA, CD, CB and CC, respectively). The synthesis of CSH was confirmed by DRX and ATR-FTIR techniques; the CSH sample presents as mesoporous with a diameter between $3.34 \mathrm{~nm}$ and $52.68 \mathrm{~nm}$ and an average size of $27.07 \mathrm{~nm}$; the specific surface area of the CSH sample was 343.99 $\mathrm{m}^{2} \mathrm{~g}^{-1}$. The formation of the CSH-nylon 6/66 nanocomposites was confirmed by ATR-FTIR, SEM, XRD, TGA, DSC and XPS techniques. The crystallization and melting temperatures ( $T_{m}$ and $T_{c}$, respectively) of CSH-nylon 6/66 nanocomposites occur at a slightly lower temperatures than those of neat Ny 6/66. These results suggest a slight decrease of the crystallite size and crystallization rate of nylon $6 / 66$. The fusion enthalpy $\left(\Delta H_{f}\right)$ decreases with increase in $\mathrm{CSH}$ content in nylon 6/66, which can be associated to a good dispersion. The XRD peaks of the nylon $6 / 66$ at $19.99^{\circ}$ and $23.77^{\circ}$ were displaced at slightly higher values of $2 \theta$ with the incorporation of $\mathrm{CSH}$ in the polymer forming nanocomposite materials.

\section{Introduction}

The interest in calcium silicates has grown in different fields such as biomaterials and wastewater treatment due to the capability of recovering phosphates from aqueous environments. Some calcium silicates like wollastonite, olivine and $\beta$ $\mathrm{CaSiO}_{3}$, have been reported as bioactive materials because of their ability to form hydroxyapatite (Hap) over their surface, but between the different types of silicates, calcium silicate hydrate $(\mathrm{CSH})$ is distinguished for the presence of -OH groups and $\mathrm{Ca}^{2+}$ ions that react with the $\mathrm{PO}_{4}{ }^{3-}$ groups providing a high bioactivity, and for that, it is considered a promising material for bone regeneration. ${ }^{1-6}$ Besides the chemical composition of the $\mathrm{CSH}$, characteristics such as specific surface area and porosity must also be considered to improve the bioactivity of the material, although there are some $\mathrm{CSH}$ with crystalline structures. The amorphous form of $\mathrm{CSH}$ can contribute to the obtaining of a porous morphology, and for that, it is necessary

\footnotetext{
${ }^{a}$ Departamento de Materiales Cerámicos Avanzados y Energía, Facultad de Ciencias Químicas, Universidad Autónoma de Coahuila, Blvd. V. Carranza s/n, 25280, Saltillo, Coahuila, Mexico. E-mail: aml15902@uadec.edu.mx; Fax: +52-84-4169213; Tel: +52-84-41383973

${ }^{b}$ Departamento de Física Aplicada, Cinvestav, Unidad Mérida, C.P. 97310, Mérida, Yucatán, Mexico

${ }^{c}$ Departamento de Materiales Avanzados, CIQA, Saltillo, Coahuila, Mexico
}

to find a synthesis method that allows the control of these properties. $^{\mathbf{1}}$

In addition to the characteristics mentioned above, the biomaterials should have good mechanical properties and be easily processed to make different pieces such as bone prosthesis or dental implants that are more durable and efficient than the ones made with conventional materials. ${ }^{7-11}$ Ceramic materials are fragile and are not suitable for use in applications that require high load. In order to improve its mechanical properties, composite materials of ceramics with polymers like chitosan, polyamides and polycaprolactone have been studied as biomaterials., ${ }^{7,12-14}$

Among the polymers used in the field of biomaterials, the polyamides, also known as nylons, are an interesting group due to their chemical structure that allow a good interaction with ceramics like HAp, also, they have shown mechanical properties similar to human bones. ${ }^{12}$ Some types of nylons that have been reported before for synthesize composite materials are nylon 12, nylon 6, and nylon 6,66 with layered silicates and organoclays. ${ }^{12,15-18}$ Nylon 6/66 composites have been synthetized before with HAp as a filler, showing good bioactivity and good mechanical properties, for that it could be possible for composite materials made with $\mathrm{CSH}$ and nylon 6/66 show good bioactive behavior and good mechanical properties.

A common method to synthetize polymer matrix composites consist in the melting of the polymer and the subsequent incorporation of the ceramic in the melted polymer, needing 
high temperatures to melt the polymer and fabricate the composite. A more facile method to synthesize this type of composites is the solution mixing method that consist in the dissolution of the polymer in an accurate solvent where the ceramic particles are dispersed. This method ensures the homogeneity of the composite. ${ }^{19}$

In this study the synthesis of nanocomposite materials of $\mathrm{CSH}$ and nylon 6/66 through a facile method is investigated for first time, with the aim to obtain new nanocomposite materials with possible applications in bone regeneration, fabrication of prosthesis and in odontology.

\section{Materials and methods}

\section{Materials}

Calcium nitrate $\left(\mathrm{Ca}\left(\mathrm{NO}_{3}\right)_{2} \cdot 4 \mathrm{H}_{2} \mathrm{O}, 99 \%\right)$, sodium meta-silicate $\left(\mathrm{Na}_{2} \mathrm{SiO}_{3}, 44-47 \% \mathrm{SiO}_{2}\right)$, sodium lauryl sulfate (SDS, 99\%), sodium hydroxide (NaOH, 99\%), nylon 6/66 (M.W. 29954 g $\mathrm{mol}^{-1}$ ), anhydrous ethanol and formic acid (95\%) were purchased from Sigma-Aldrich.

\section{Synthesis of CSH by hydrolysis and ion exchange}

$\mathrm{CSH}$ was synthetized by a modification of the method reported by Mehrali et al. ${ }^{20}$ A solution $0.2 \mathrm{M}$ of $\mathrm{Ca}\left(\mathrm{NO}_{3}\right)_{2}$ was prepared and the $\mathrm{pH}$ value was adjusted to 9 with a solution $0.1 \mathrm{M}$ of $\mathrm{NaOH}$; after that, SDS was added in a concentration equal to its critical micellar concentration (CMC). Subsequently, a solution $0.2 \mathrm{M}$ of $\mathrm{Na}_{2} \mathrm{SiO}_{3}$ was mixed with the solution of $\mathrm{Ca}\left(\mathrm{NO}_{3}\right)_{2}$ and the mixture was left under ultrasonic irradiation (SONICS, Ultrasonic Processor, 20\% amplitude, $750 \mathrm{~W}$ ) for $15 \mathrm{~min}$ at $85{ }^{\circ} \mathrm{C}$. The obtained white product was washed with deionized water and ethanol to eliminate the surfactant and finally it was dried in an oven at $120^{\circ} \mathrm{C}$ for 2 hours.

\section{Synthesis of CSH-nylon 6/66 nanocomposite materials by solution mixing method}

A previously established amount of nylon 6/66 pellets was dissolved in $6 \mathrm{ml}$ of formic acid; after that, a suspension prepared with $0.2 \mathrm{~g}$ of the $\mathrm{CSH}$ into $15 \mathrm{ml}$ of ethanol was added to the solution and the mixture was left under stirring for $15 \mathrm{~min}$ at $35{ }^{\circ} \mathrm{C}$. Next, the temperature was raised to $45^{\circ} \mathrm{C}$ and the stirring was turned off for 24 hours to evaporate the solvent. The white film obtained was then washed with deionized water and dried in an oven at $100{ }^{\circ} \mathrm{C}$ for 2 hours. Table 1 shows the synthesis conditions used to obtain four different composite materials and the synthesis procedure is schematized in Fig. 1.

Table 1 Synthesis conditions used to obtain CSH-nylon 6/66 nanocomposites

\begin{tabular}{lll}
\hline Sample & Nylon 6/66 weight $\%$ & CSH weight \% \\
\hline CA & 75 & 25 \\
CD & 50 & 50 \\
CB & 25 & 75 \\
CC & 2.5 & 97.5
\end{tabular}

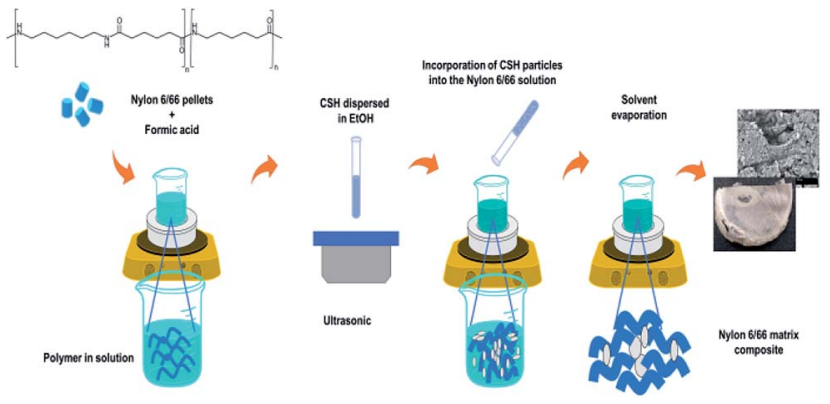

Fig. 1 Synthesis procedure used for the obtention of CSH-nylon 6/66 nanocomposite materials.

\section{Characterization}

The FTIR spectra were obtained with a Thermo Scientific spectrometer in the ATR modality. A X-ray diffractometer Rigaku Ultima IV $\left(\mathrm{Cu} \mathrm{K} \alpha, 10^{\circ} \mathrm{min}^{-1}, 2\right.$ theta/theta, D-Tex, $40 \mathrm{KV}$, $44 \mathrm{~mA}$ ) was used to characterize the calcium silicate sample and their composites with nylon 6/66. The nitrogen adsorption/ desorption isotherm of calcium silicate sample was obtained

\section{A}

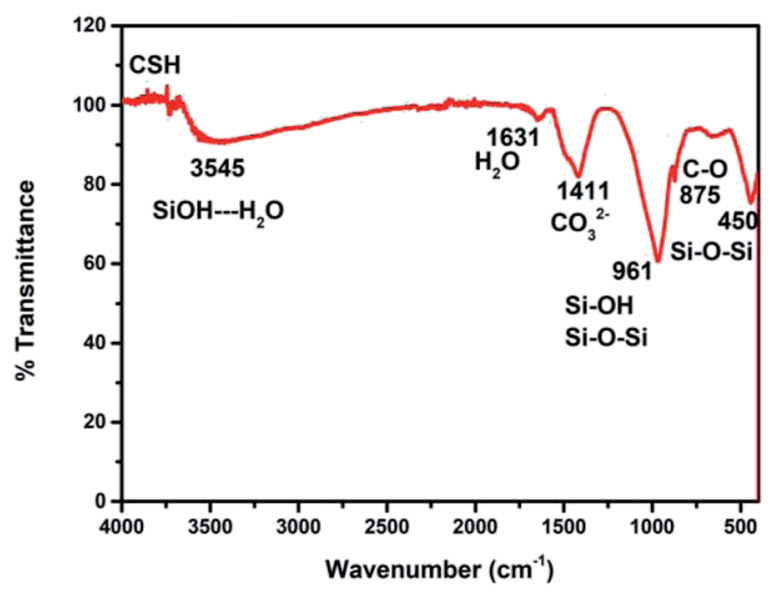

B

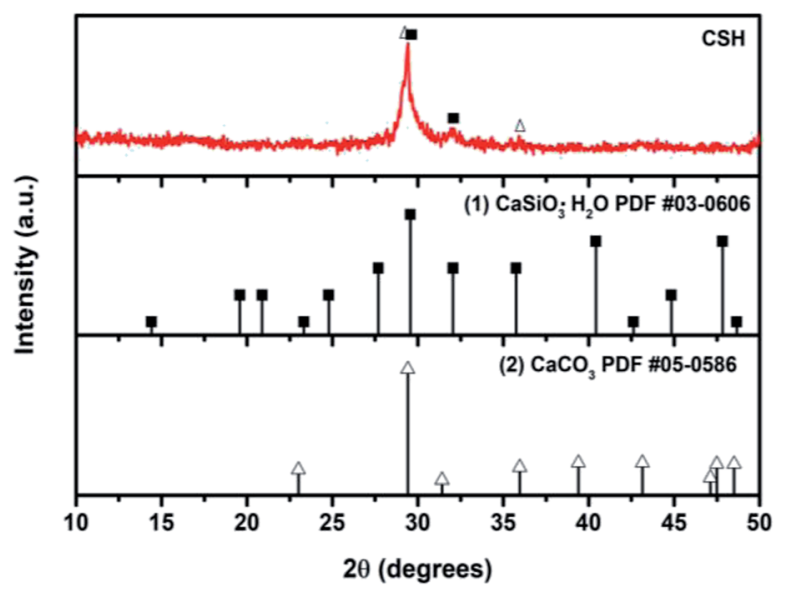

Fig. 2 (A) ATR-FTIR spectrum and (B) XRD pattern of the calcium silicate hydrated $(\mathrm{CSH})$. 


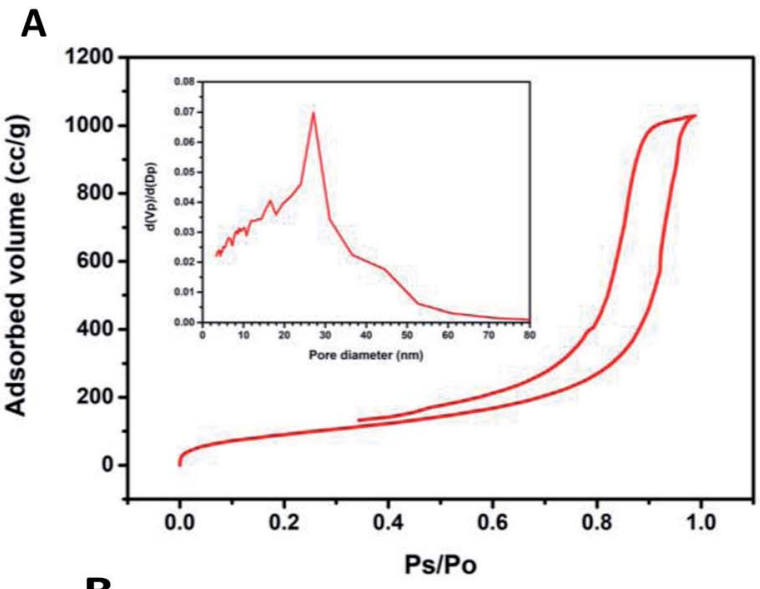

B

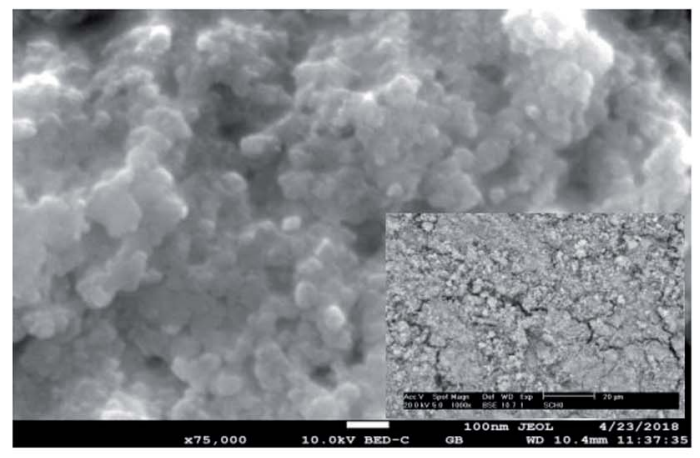

C

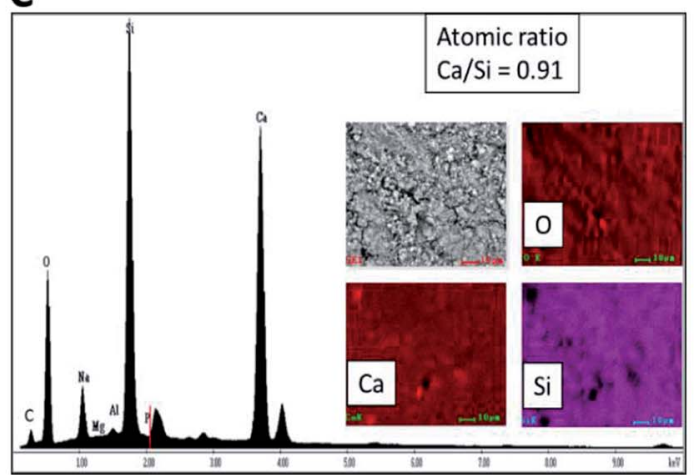

Fig. 3 (A) Adsorption-desorption isotherm and pore size distribution, (B) SEM micrograph at $75000 \times$ (inserted micrograph was obtained at $1000 \times$ ) and (C) Energy spectrum and element mapping images of $\mathrm{Si}$, $\mathrm{Ca}$ and $\mathrm{O}$ of the $\mathrm{CSH}$.

using a Beckman Coulter SA3100 equipment. The morphology of the samples was investigated with an electronic microscope Philips XL 30 ESEM, equipped with an energy-dispersive X-ray (EDX) microanalysis system.

The thermal stability of CSH, nylon 6/66 and CSH-nylon 6/66 nanocomposites was determined using thermogravimetric analysis (TGA). Thermogravimetric measurements were performed using a PerkinElmer, TGA 4000 thermogravimetric analyser from 25 to $800{ }^{\circ} \mathrm{C}$ with a heating rate of $10{ }^{\circ} \mathrm{C} \mathrm{min}{ }^{-1}$ and nitrogen gas flow rate of $20 \mathrm{~cm}^{3} \mathrm{~min}^{-1}$. Differential scanning calorimetry (DSC) was employed to investigate the effect of $\mathrm{CSH}$ on the melting and crystallization behavior of nylon 6/66.
Samples of neat nylon 6/66, CB and CD were studied using a TA Instruments DSC model Discovery 2500, using a heating and cooling rate of $10^{\circ} \mathrm{C} \mathrm{min}^{-1}$ between 30 and $300^{\circ} \mathrm{C}$ under an inert nitrogen atmosphere. The samples were held at $300{ }^{\circ} \mathrm{C}$ for 5 min prior to cooling to remove previous thermal history. The samples were then cooled to $30^{\circ} \mathrm{C}$ at $10^{\circ} \mathrm{C} \mathrm{min}^{-1}$ and reheated again to $300{ }^{\circ} \mathrm{C}$ at $10^{\circ} \mathrm{C} \mathrm{min}^{-1}$.
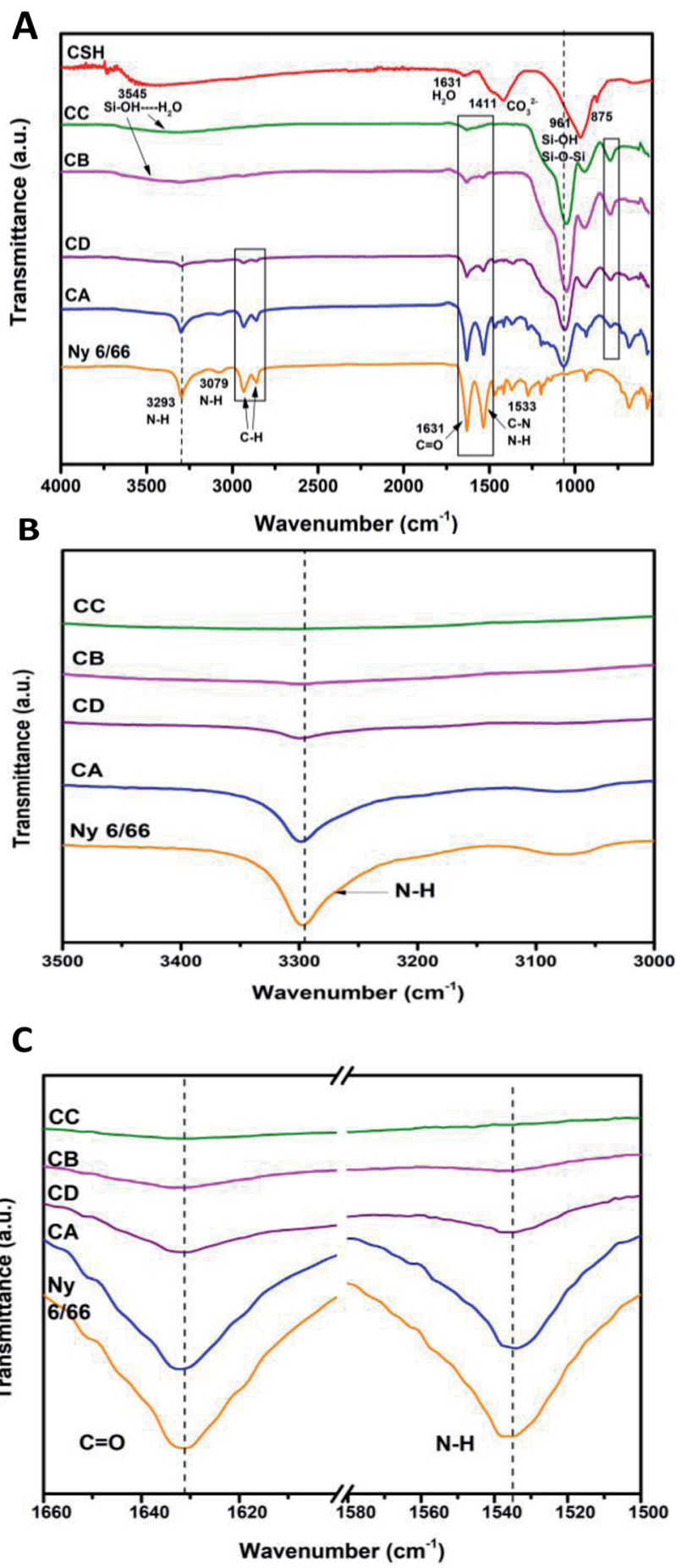

Fig. 4 (A) ATR-FTIR spectra of the samples CA, CB, CD, CC and Ny 6/ 66 from 4000 to $400 \mathrm{~cm}^{-1}$; (B) spectra from 3500 to $3000 \mathrm{~cm}^{-1}$ and (C) spectra from 1660 to $1500 \mathrm{~cm}^{-1}$. 
Table 2 Characteristic vibration frequencies $\left(\mathrm{cm}^{-1}\right)$ in FTIR-ATR spectra of the synthetized samples ${ }^{16,20-23,29-32}$

Samples synthetized in this work

\begin{tabular}{|c|c|c|c|c|c|c|c|}
\hline Assignments & $\mathrm{CA}$ & $\mathrm{CD}$ & $\mathrm{CB}$ & $\mathrm{CC}$ & Ny 6/66 & $\mathrm{CSH}$ & Literature \\
\hline $\mathrm{N}-\mathrm{H}$ overtone of amide II & 3077 & - & - & - & 3079 & - & $3070-3082$ \\
\hline CH methylene symmetric stretching & 2859 & 2862 & - & - & 2859 & - & $2851-2860$ \\
\hline $\mathrm{C}=\mathrm{O}$ stretching amide $\mathrm{I}$ & 1633 & 1633 & 1633 & 1633 & 1631 & - & $1632-1660$ \\
\hline $\begin{array}{l}\mathrm{C}-\mathrm{N} \text { stretching and } \mathrm{N}-\mathrm{H} \text { bending amide } \\
\mathrm{II}\end{array}$ & 1534 & 1537 & 1538 & - & 1533 & - & $1530-1537$ \\
\hline $\mathrm{CH}_{2}$ wagging & 1367 & 1363 & - & - & 1371 & - & $1370-1373$ \\
\hline Amide III & 1274 & - & - & - & 1270 & - & $1262-1279$ \\
\hline $\mathrm{Si}-\mathrm{OH} \cdots \mathrm{H}_{2} \mathrm{O}$ & - & - & $3500-3100$ & $3500-3100$ & - & 3545 & $2800-3700$ \\
\hline $\mathrm{H}_{2} \mathrm{O}$ molecular & - & - & - & - & - & 1631 & $1600-1650$ \\
\hline $\mathrm{CO}_{3}{ }^{2-}$ asymmetric stretching & - & - & - & - & - & 1411 & $1410-1510$ \\
\hline $\mathrm{Si}-\mathrm{O}-\mathrm{Si}$ stretching & 1066 & 1060 & 1050 & 1047 & - & - & 1095-900 \\
\hline
\end{tabular}

Chemical binding was analyzed by X-ray photoelectron spectroscopy (XPS) performed with a Thermo Scientific equipment, under high vacuum $\left(9.5 \times 10^{-9} \mathrm{mbar}\right)$ operating with $\mathrm{Al}$ $\mathrm{K} \alpha$ radiation at $12 \mathrm{KV}$ and $40 \mathrm{~W}$; each sample was sputtered 15 seconds for a better analysis of the surface.

\section{Results and discussion}

\section{Characterization of CSH}

Fig. 2A shows the ATR-FTIR spectrum of the sample of calcium silicate. The band at $961 \mathrm{~cm}^{-1}$, can be attributed to a coupling of the vibrations of the $\mathrm{Si}-\mathrm{O}-\mathrm{Si}, \mathrm{Si}-\mathrm{OH}$ and $\mathrm{Si}(\mathrm{OSi})_{3} \mathrm{O}-\mathrm{Ca}$ groups. The band at $3545 \mathrm{~cm}^{-1}$ is attributed to the stretching vibration of $\mathrm{Si}-\mathrm{OH} \cdots \mathrm{H}_{2} \mathrm{O}$, this band and the one at $1631 \mathrm{~cm}^{-1}$ indicate the presence of water in the chemical structure of calcium silicate. Absorption band at $1411 \mathrm{~cm}^{-1}$ corresponding to the binding vibration of the $\mathrm{C}-\mathrm{O}$ indicates the presence of $\mathrm{CO}_{2}{ }^{3-}$ groups, this is because the sample adsorbs $\mathrm{CO}_{2}$, and due to its nature, it is not possible to avoid this phenomenon once it is exposed to the environment. ${ }^{20-25}$ The diffraction pattern of the sample of calcium silicate is show in Fig. 2B; the presence of $\mathrm{CSH}\left(\mathrm{CaSiO}_{3} \cdot \mathrm{H}_{2} \mathrm{O}\right.$ PDF \#03-0606) was identified. Also, calcium carbonate is presented $\left(\mathrm{CaCO}_{3}, \mathrm{PDF} \# 05-0586\right)$; the formation of this phase maybe took place during the synthesis process, where $\mathrm{CO}_{2}$ from the atmosphere was absorbed due to the elevated $\mathrm{pH}$ conditions. The low-intensity diffraction peak at $2 \theta=29.4^{\circ}$ indicates low crystallinity of CSH.

Specific surface area was estimated according to BrunauerEmmet-Teller (BET) method and the pore size distribution was calculated according to the Barret-Joyner-Halenda (BJH) model with the data of the nitrogen desorption isotherm. The nitrogen adsorption/desorption isotherm presented in Fig. 3A corresponds to a type IV isotherm according to the IUPAC classification, which is characteristic of a mesoporous solid.
The pore size distribution indicates that the CSH sample presents porous with a diameter between $3.34 \mathrm{~nm}$ and $52.68 \mathrm{~nm}$ and an average size of $27.07 \mathrm{~nm}$. The specific surface area obtained was $343.99 \mathrm{~m}^{2} \mathrm{~g}^{-1}$, this result can ensure a higher bioactivity due to the increase of sites for formation of Hap; also the presence of mesoporous is a suitable characteristic for biomaterials for bone regeneration because they allow the free movement of biomolecules like proteins and induce the adhesion of cells..$^{\mathbf{8} 26-28}$ The SEM image shown in Fig. 3B suggests that the $\mathrm{CSH}$ consists of agglomerated nanoparticles and it has high porosity. Energy spectrum and element mapping images of $\mathrm{Si}$, $\mathrm{Ca}$ and $\mathrm{O}$ of the $\mathrm{CSH}$ are shown in Fig. 3C. The value of the atomic ratio of $\mathrm{Ca} / \mathrm{Si}$ is equal to 0.91 , which is close to the expected theoretical value of 1 ; the difference between both values is due to EDX microanalysis is not a quantitative technique.

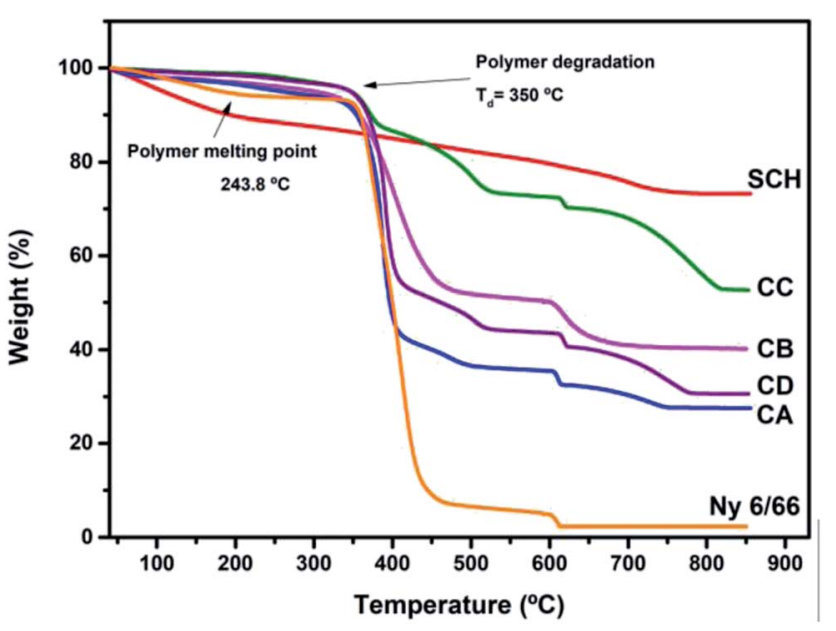

Fig. 5 TG curves of the samples CA, CB, CC and CD and TG curves of nylon 6/66 (Ny 6/66) and the CSH. 
A

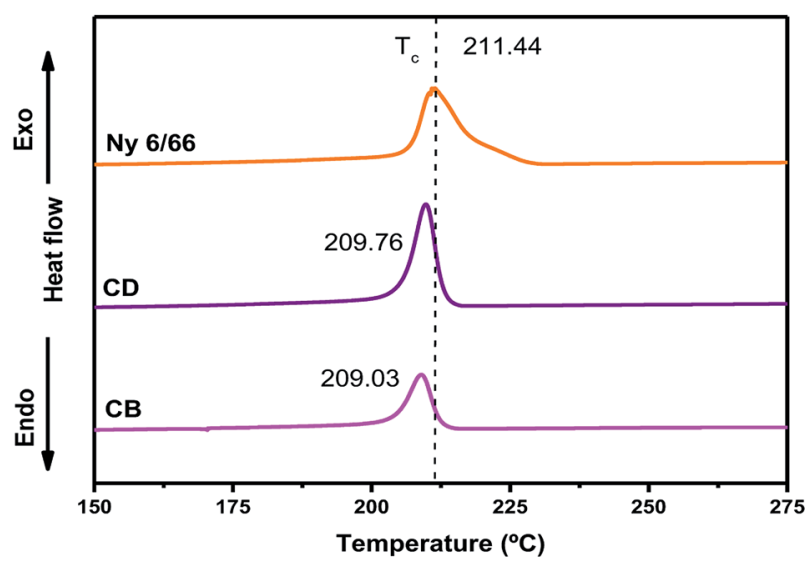

B

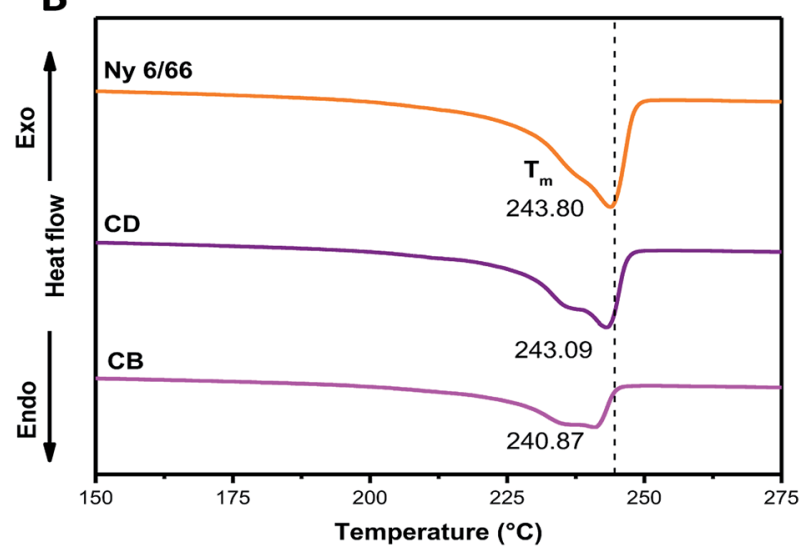

Fig. 6 DSC curves of the nylon 6/66 and CSH-nylon 6/66 nanocomposites during the first cooling (A) and second heating (B) scans.

\section{Characterization of CSH-nylon 6/66 nanocomposite materials}

The ATR-FTIR spectrum of the CSH and ATR-spectra of the samples CA, CB, CC and CD are presented in Fig. 4A. It can be observed that the characteristic bands of the amide at 3293, 1631 and $1533 \mathrm{~cm}^{-1}(\nu \mathrm{N}-\mathrm{H}, \nu \mathrm{C}=\mathrm{O}, \nu \mathrm{C}-\mathrm{N}$ and $\delta \mathrm{N}-\mathrm{H})$ are displaced to higher wave number as the amount of $\mathrm{CSH}$ increases (see Fig. 4B and C).

The typical bands of the methylene groups at 2933 and $2859 \mathrm{~cm}^{-1}$, corresponding to the asymmetric and symmetric vibrations of $\mathrm{C}-\mathrm{H}$ are also displaced to higher wave number. In

Table 3 DSC data of the Ny 6/66 and the CSH-nylon 6/66 nanocomposites. The crystallization temperature $\left(T_{\mathrm{c}}\right)$ was recorded from the first cooling scan; the melting point $\left(T_{m}\right)$ and fusion enthalpy $\left(\Delta H_{f}\right)$ were recorded from the second heating scan

\begin{tabular}{llll}
\hline Sample & $T_{\mathrm{c}}\left({ }^{\circ} \mathrm{C}\right)$ & $T_{\mathrm{m}}\left({ }^{\circ} \mathrm{C}\right)$ & $\Delta H_{\mathrm{f}}\left(\mathrm{J} \mathrm{g}^{-1}\right)$ \\
\hline Ny 6/66 & 211.44 & 243.80 & 76.086 \\
CD & 209.76 & 243.09 & 57.207 \\
CB & 209.03 & 240.87 & 37.212 \\
Ny 6/66 (ref. 17) & 118.7 & 193.5 & 32.8 \\
Ny 6/66 (ref. 18) & 157 & 194 & 47.8
\end{tabular}

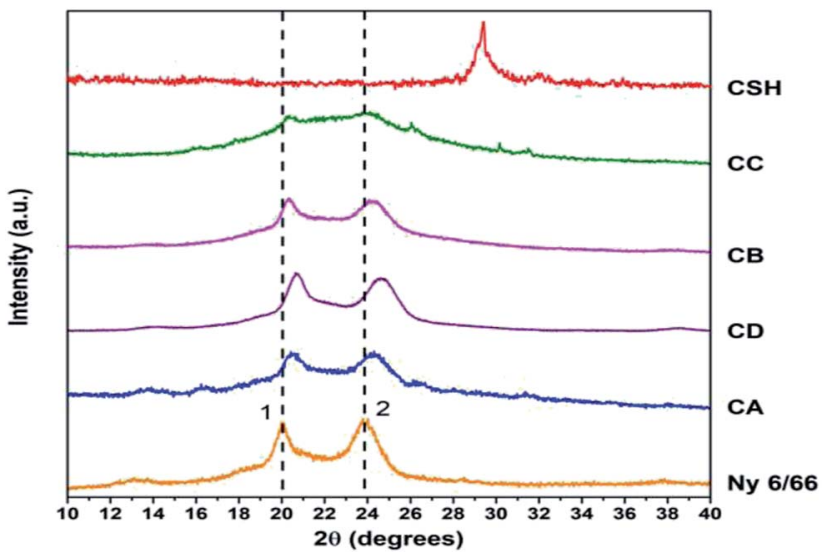

Fig. 7 XRD patterns of the samples of $C A, C B, C C$ and $C D$ and XRD patterns of the precursors.

the composite materials the band at $961 \mathrm{~cm}^{-1}$ is not present, but the appearance of the typical bands of the $\mathrm{Si}-\mathrm{O}-\mathrm{Si}$ are clearly presented from 1066 to $1047 \mathrm{~cm}^{-1}$ and 794 to $792 \mathrm{~cm}^{-1}$. Therefore, it can be inferred that the interaction between nylon 6/66 and CSH occurs trough amide groups of nylon 6/66 with Si$\mathrm{OH}$ groups of the $\mathrm{CSH}$. Table 2 shows the characteristic vibration frequencies in ATR-FTIR spectra of the samples CA, CB, CC and $\mathrm{CD}$ and the assignments according to the literature. ${ }^{16,20-23,29-32}$

In the thermogravimetric curves (Fig. 5) a main weight loss can be seen between $350{ }^{\circ} \mathrm{C}$ and $550{ }^{\circ} \mathrm{C}$ for the nylon $6 / 66$ and the samples $\mathrm{CA}, \mathrm{CB}, \mathrm{CC}$ and $\mathrm{CD}$, this is due to the decomposition of the polymer chains. The starting degradation temperature of the pristine nylon $6 / 66$ take place at $350{ }^{\circ} \mathrm{C}$, this temperature value decreases for the samples $\mathrm{CA}, \mathrm{CB}, \mathrm{CC}$ and $\mathrm{CD}$, having the lower degradation temperature for $\mathrm{CB}$ sample at $333^{\circ} \mathrm{C}$ and the higher initial degradation temperature for $\mathrm{CC}$ sample at $348{ }^{\circ} \mathrm{C}$. However, the final degradation temperature of the nylon $6 / 66$ at $445{ }^{\circ} \mathrm{C}$, increases as the amount of CSH in the polymer matrix increases too, obtaining the higher final degradation temperature in sample $\mathrm{CC}$ at $527^{\circ} \mathrm{C}$. This indicates that the samples $\mathrm{CA}, \mathrm{CB}, \mathrm{CC}$ and $\mathrm{CD}$ are thermally stable in a longer range of temperature, which can be due to the formation of bonds between the nylon 6/66 and the CSH. A second weight loss is seen in the TG curve of nylon 6/66; this loss starts at $603{ }^{\circ} \mathrm{C}$ and in this case the initial degradation temperature

Table $42 \theta$ values of the $\mathrm{Ny} 6 / 66$ and the $\mathrm{CSH}$-nylon 6/66 nanocomposites (CA, CD, CB and CC)

\begin{tabular}{lll}
\hline & \multicolumn{2}{l}{$2 \theta$ degrees } \\
\cline { 2 - 3 } Sample & Peak 1 & Peak 2 \\
\hline Ny 6/66 & 19.99 & 23.77 \\
CA & 20.42 & 24.30 \\
CD & 20.64 & 24.62 \\
CB & 20.34 & 24.06 \\
CC & 20.36 & 24.14
\end{tabular}


increases as the amount of $\mathrm{CSH}$ increases too, obtaining the higher initial degradation temperature in the composite CC at $613{ }^{\circ} \mathrm{C}$. All samples of CSH-nylon 6/66 present higher thermal stability than pristine nylon 6/66. For the CSH a total weight loss of $30 \%$ occurs mainly due to the evaporation of adsorbed water and water bonded to the crystalline structure. After the degradation of the polymer matrix, some changes still occur in the composite materials such as the change of phase from $\mathrm{CSH}$ to wollastonite type silicate. ${ }^{33-36}$

The DSC curves of neat nylon 6/66 and of the samples CB and $\mathrm{CD}$ during the first cooling and second heating processes are shown in Fig. 6A and B, respectively. Table 3 summarizes the data from the DSC curves. The crystallization temperature $\left(T_{\mathrm{c}}\right)$ of the samples CB and CD occurs at a slightly lower temperature than that of neat Ny 6/66. The high quantity of CSH added could deaccelerate the Ny 6/66 nucleation rate and consequently lead to the decrease of the crystallization rate, and as a result, the $T_{\mathrm{c}}$ during the cooling decreased. Also, the addition of $\mathrm{CSH}$ had a slight impact on the melting temperature $\left(T_{\mathrm{m}}\right)$; this may be is related to a slight reduction in crystallite size with the presence of $\mathrm{CSH}$ in the nanocomposites and consequently lead to the lower $T_{\mathrm{m}}$ value. However, an obvious decrease in the fusion enthalpy $\left(\Delta H_{\mathrm{f}}\right)$ was observed, due to the addition of CSH. This observation is in according to Venkataramani et al., (2009); they study the structure and properties of nylon 6/66 with a molecular weight of $35721.92 \mathrm{~g} \mathrm{~mol}^{-1}$ and a nylon 6/66 organoclay composite $(2 \%)$. The fusion enthalpy $\left(\Delta H_{\mathrm{f}}\right)$ and melting temperature decrease with increase in clay content in nylon 6/ 66. ${ }^{17}$ Liu et al. (2018) investigated on crystallization of nylon 6/66 nanocomposites with exfoliated organoclay into the range of 1 to 5 weight percent, which was introduced and melt-blended with PA6/66 $\left(M_{\mathrm{n}}=17000 \mathrm{~g} \mathrm{~mol}^{-1}\right)$; they reported that $T_{\mathrm{c}}$ during the cooling increases. ${ }^{18}$
The Fig. 7 shows the XRD patterns of the samples CA, CB, CC and $\mathrm{CD}$; XRD patterns of nylon 6/66 and $\mathrm{CSH}$ are also included. It is seen that the XRD pattern for nylon 6/66 shows its crystalline nature with the characteristic peaks at $2 \theta=19.99^{\circ}$ and $23.77^{\circ}$ which belong to the monoclinic form; similar results have been reported for PA6/66 and its nanocomposites with different organoclay content. ${ }^{17}$ It is noticed that the two peaks of the nylon 6/66 are slightly shifted towards higher $2 \theta$ values with the incorporation of $\mathrm{CSH}$ in the composition of the samples CA, CB, CD and CC (see Table 4). This suggests that CSH was incorporated to nylon 6/66 forming composite materials. XRD pattern of sample CC also shows two small diffraction peaks at $26^{\circ}$ and $30^{\circ}$ that correspond to the presence of calcium formate, a subproduct from the reaction between $\mathrm{CaCO} 3$ present in the $\mathrm{CSH}$ sample and the formic acid used to dissolve the nylon 6/66. Calcium formate is soluble in water at $25^{\circ} \mathrm{C}$, therefore, it is possible to eliminate it easily.

The morphology of the samples CA, CB, CC and CD was investigated by scanning electron microscopy (SEM). The Fig. 8 show the micrograph of the samples CA, CD, CB and CC. Also, energy spectra and element mapping images of $\mathrm{Si}$ and $\mathrm{C}$ of these samples are shown in this figure. It is observed that the samples CA and CD consist of a polymer matrix that is filled with very few agglomerates of CSH. The samples $\mathrm{CB}$ and CC consists of a ceramic matrix with a high amount of $\mathrm{CSH}$ particles. The morphology of the sample CD is very different to the other and it has more porous; this sample was possibly exposed to a longer analysis time by SEM and the energy of the beam could have burned it, leaving pores. The energy peaks corresponding to $\mathrm{Si}, \mathrm{Ca}, \mathrm{C}$ and $\mathrm{O}$ are observed in the energy spectra of the samples CA, CD, CB and CC. A semiquantitative analysis of the atomic ratio of $\mathrm{Si}: \mathrm{C}$ for the samples $\mathrm{CA}, \mathrm{CD}, \mathrm{CB}$ and $\mathrm{CC}$ was performed and values of $0.045,0.119,0.648$ and 1.007,
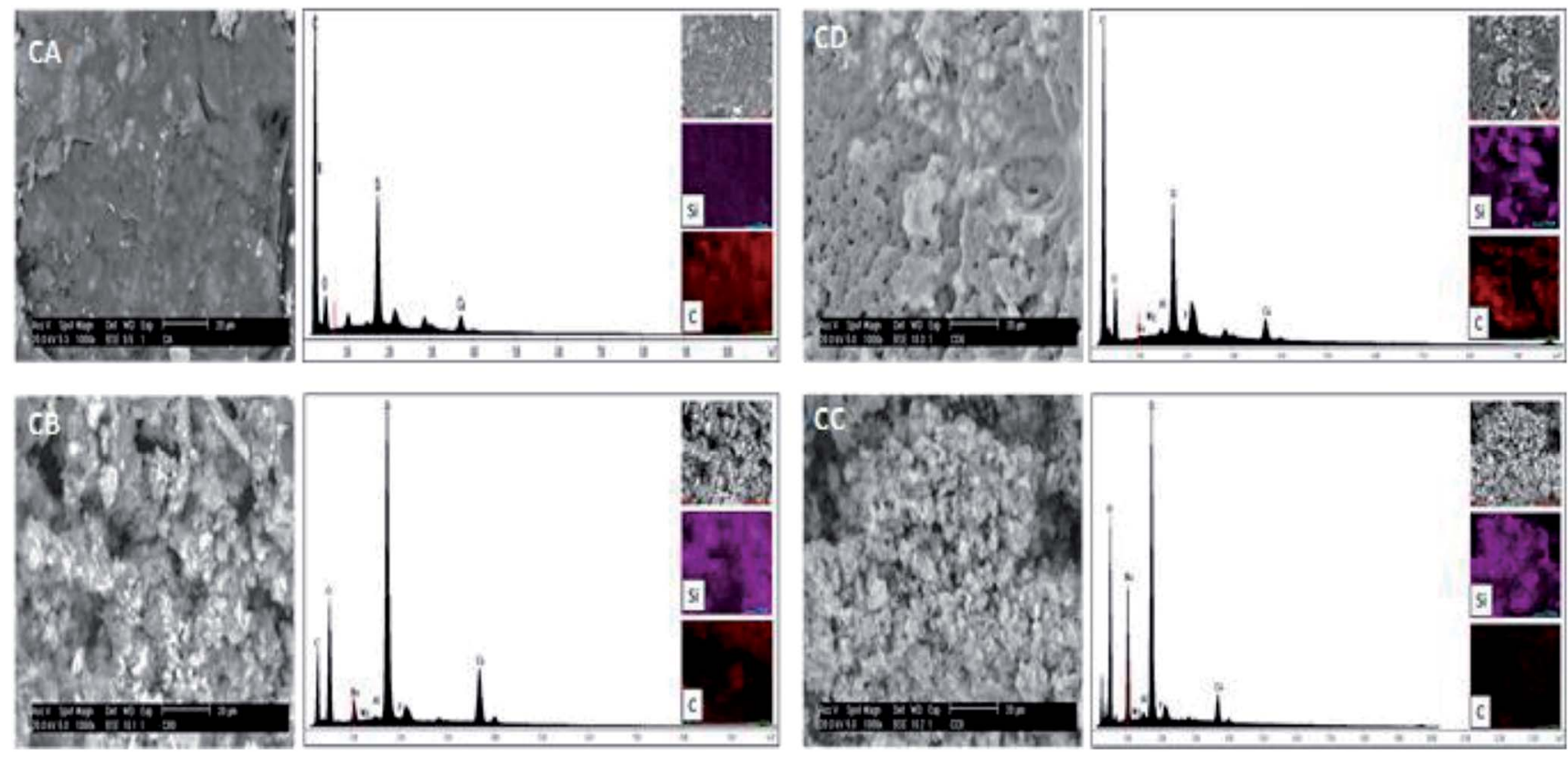

Fig. 8 SEM micrographs, energy spectra and element mapping images of Si and $C$ of the samples $C A, C B, C C$ and $C D$. 
A

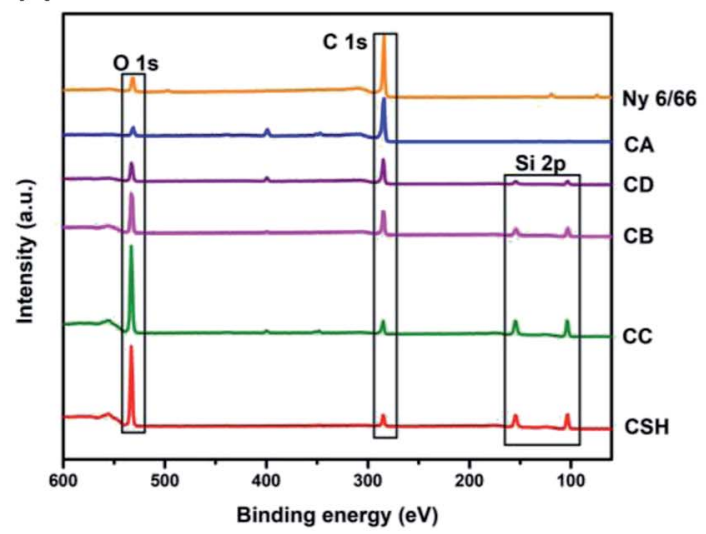

C
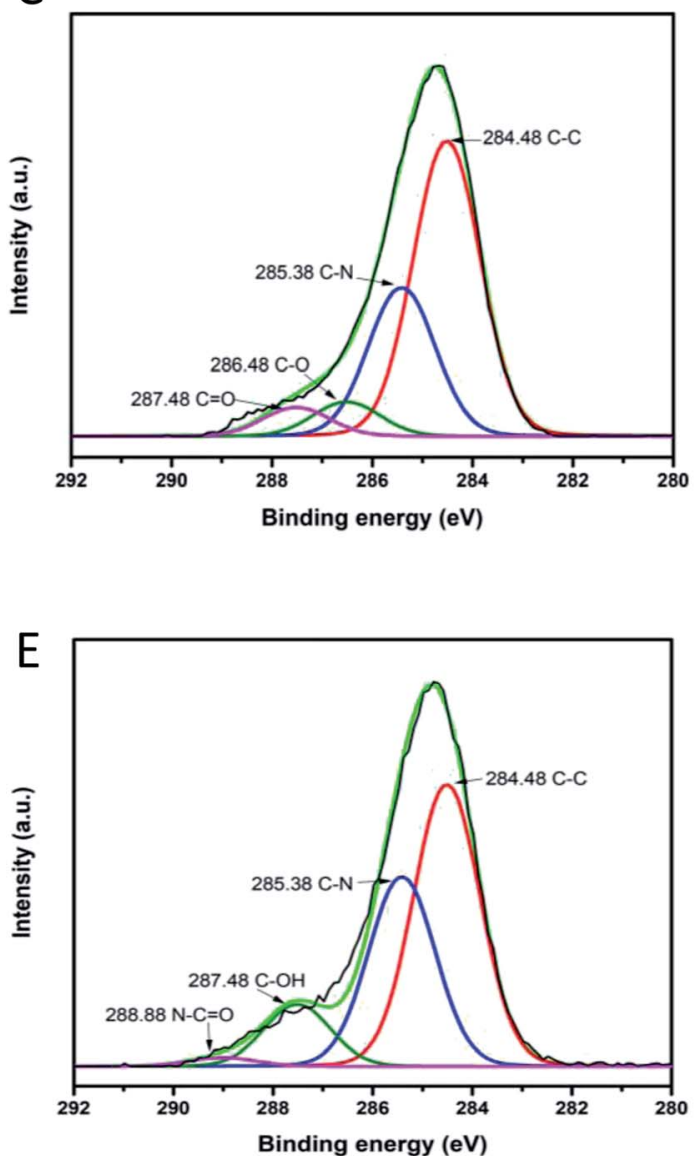

B

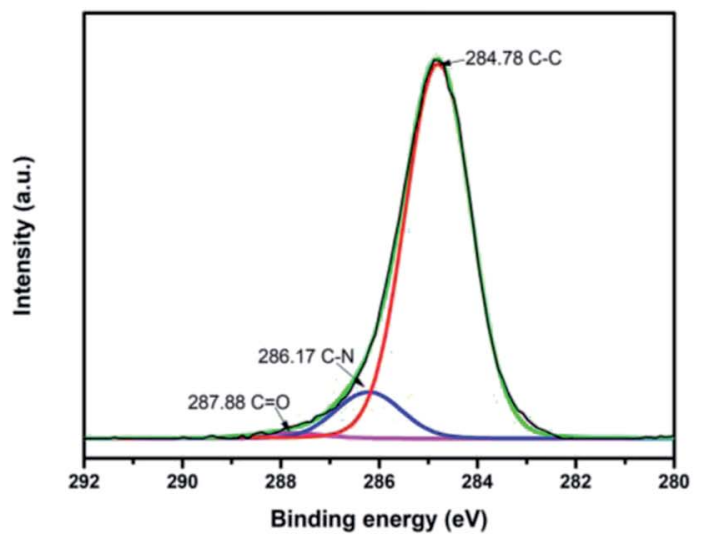

D

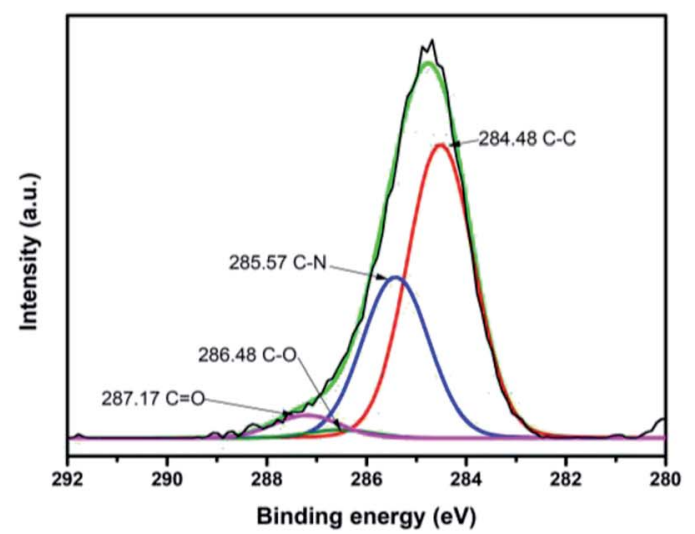

$F$

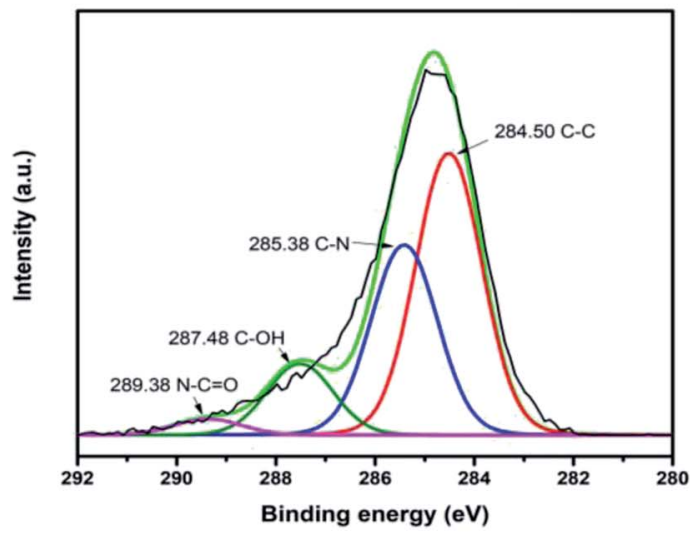

Fig. 9 (A) General XPS binding energy spectra of the samples CA, CB, CC and CD and XPS spectra of pristine nylon 6/66 and the CSH; and deconvolution of carbon 1s peak of (B) nylon 6/66, (C) composite CA, (D) composite CD, (E) composite CB and (F) composite CC.

respectively, were obtained. These measured values are lower than the expected theoretical values of $0.097,0.194,0.972$ and 7.775 for the samples CA, CD, CB and CC, respectively, because EDX microanalysis is not a quantitative technique. The element mapping images of Si and C of the samples CA, CD, CB and CC suggest that they are homogeneous in their chemical composition.

To investigate the chemical environment in the surface of the samples $\mathrm{CA}, \mathrm{CB}, \mathrm{CC}$ and $\mathrm{CD}$, one XPS analysis was performed; the results are shown in Fig. 9. In the XPS binding energy spectra of the samples CA, CB, CC and CD the appearance of the peaks of Si 2 p and the increasing of the intensity of the peak of $\mathrm{O} 1 \mathrm{~s}$ can be seen; the displacement of the $\mathrm{O} 1 \mathrm{~s}$ and the $\mathrm{C}$ 1s peaks shows the changing on the chemical environment in the surface of the samples (Fig. 9A). The deconvolution of the peak $\mathrm{C} 1 \mathrm{~s}$ for the samples $\mathrm{CA}, \mathrm{CB}, \mathrm{CC}$ and $\mathrm{CD}$ is presented in Fig. 9B-F. The peak of the $\mathrm{C} 1$ s on the pristine nylon 6/66 was deconvoluted into three signals indicating the presence of $\mathrm{C}=$ 

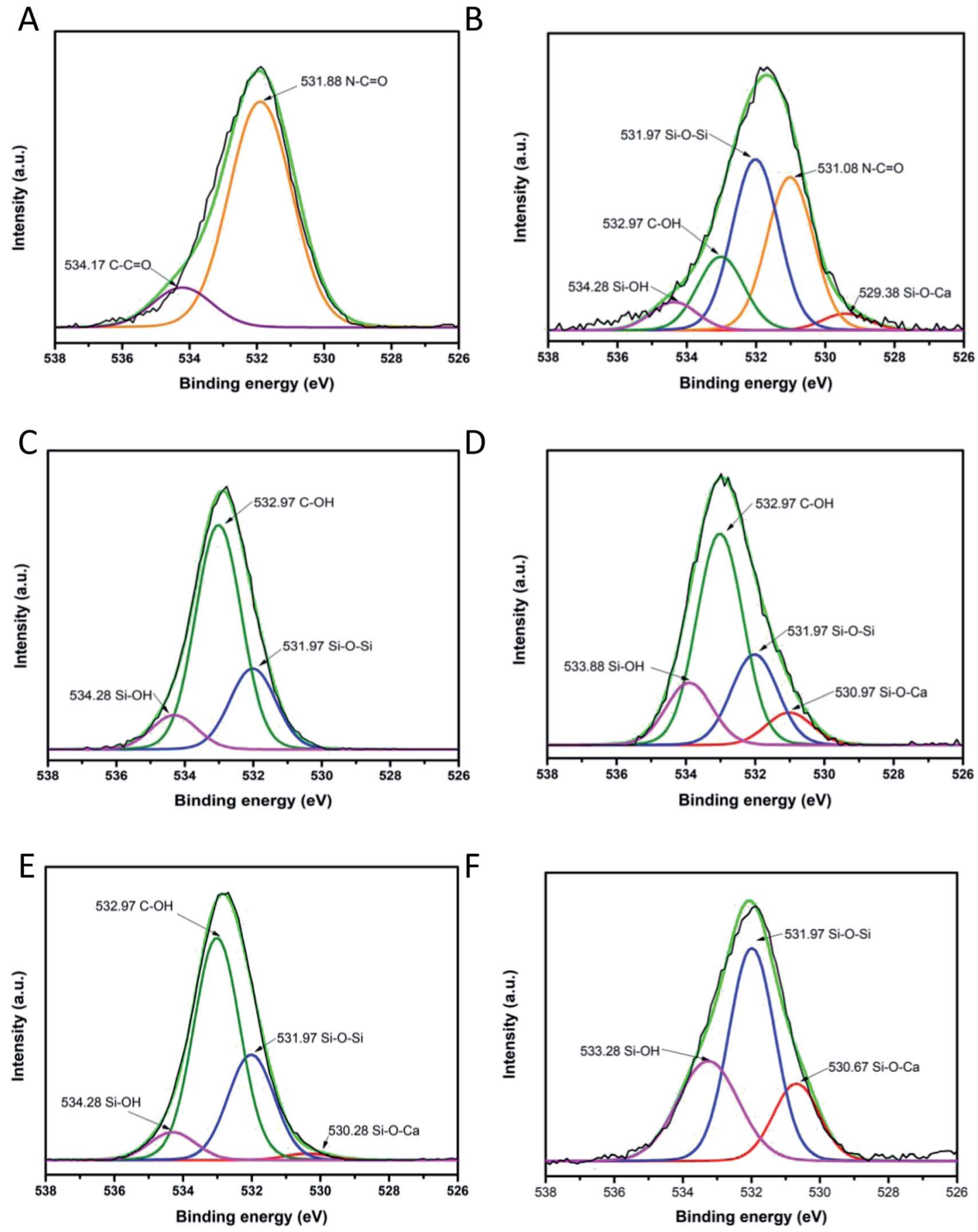

Fig. 10 Deconvolution of $\mathrm{O}$ 1s peak of (A) pristine nylon 6/66, (B) composite $C A$, (C) composite $C D$, (D) composite CB, (E) composite CC and (F) CSH.

$\mathrm{O}, \mathrm{C}-\mathrm{N}$ and $\mathrm{C}-\mathrm{C}$ bonds (Fig. 9B). The signal of $\mathrm{C}-\mathrm{O}$ bonding appears with the addition of the $\mathrm{CSH}$ to the polymer (samples $\mathrm{CA}, \mathrm{CB}, \mathrm{CC}$ and $\mathrm{CD}$ ), which indicates the formation of new bonds between the carbon atoms of the polymer chain and the groups $-\mathrm{OH}$ of the $\mathrm{CSH}$ (Fig. 9C-F). The $\mathrm{O}$ 1s peak of spectra of pristine nylon 6/66 and the $\mathrm{CSH}$ and the $\mathrm{O}$ 1s peak of spectra of the samples CA, CB, CC and CD was also deconvoluted (Fig. 10). It is observed that there are two oxygen environments in the spectra of pristine nylon 6/66 that corresponding to $\mathrm{N}-\mathrm{C}=\mathrm{O}$ and $\mathrm{C}=\mathrm{O}$ bonds. XPS spectra of the samples $\mathrm{CA}, \mathrm{CB}, \mathrm{CC}$ and $\mathrm{CD}$ have three other signals that corresponding to $\mathrm{Si}-\mathrm{O}-\mathrm{Ca}, \mathrm{Si}-\mathrm{O}-\mathrm{Si}$ and $\mathrm{Si}-\mathrm{OH}$ bonds from the $\mathrm{CSH}$. The intensity of the signal of $\mathrm{Si}-\mathrm{O}-\mathrm{Ca}$ decreases as the amount of nylon 6/66 increases. Intensity of the signal of $\mathrm{Si}-\mathrm{OH}$ of the $\mathrm{CSH}$ decreases as well as the intensity of the signal $\mathrm{Si}-\mathrm{O}-\mathrm{Ca}$ of the samples $\mathrm{CA}, \mathrm{CB}, \mathrm{CC}$ and CD.

Based on the results of the ATR-FTIR spectra, XRD and XPS analysis of the spectra of the samples CA, CB, CC y CD, a structure of CSH-nylon 6/66 nanocomposites is proposed in Fig. 11. 


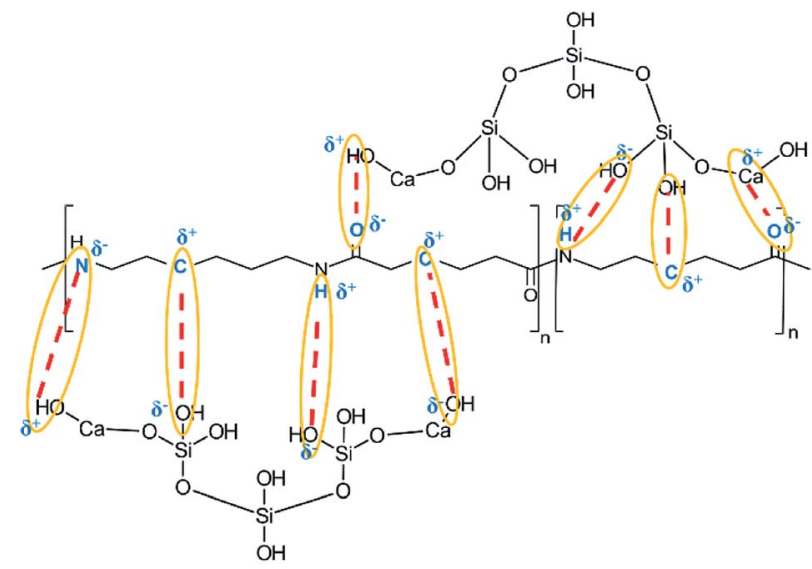

Fig. 11 Representation of the bonds between the CSH and nylon 6/66 in the composite materials.

\section{Conclusions}

According to the ATR-FTIR spectra, XRD patterns and the XPS analysis, it can be assumed that the solution mixing method, using formic acid to dissolve the nylon $6 / 66$, allowed to easily synthetize CSH-nylon 6/66 nanocomposites. The synthesis of CSH-nylon 6/66 nanocomposites took place by the interaction between calcium atoms from the $\mathrm{CSH}$ with oxygen atoms from the nylon, as well as by the interactions between groups $\mathrm{Si}-\mathrm{OH}$ from the $\mathrm{CSH}$ with groups $-\mathrm{NH}$ from the polymer chain. The incorporation of the $\mathrm{CSH}$ to nylon 6/66 increases its thermal stability. The crystallization and melting temperatures $\left(T_{\mathrm{m}}\right.$ and $T_{\mathrm{c}}$, respectively) of $\mathrm{CSH}$-nylon 6/66 nanocomposites occurs at a slightly lower temperature than that of neat Ny 6/66. These results suggest a slight decrease of the crystallite size and crystallization rate of nylon 6/66. Due to the high value of specific surface area of the CSH $\left(343.99 \mathrm{~m}^{2} \mathrm{~g}^{-1}\right)$ and the chemical structure of CSH-nylon 6/66 nanocomposites, they can be used in the fabrication of bone prosthesis and odontology implants.

\section{Conflicts of interest}

There are no conflicts to declare.

\section{Acknowledgements}

S. Estrada-Flores thanks to the National Council of Science and Technology from Mexico (CONACYT) for the scholarship (446796).

\section{References}

1 P. Siriphannon, Y. Kameshima and A. Yasumori, J. Eur. Ceram. Soc., 2002, 22, 511-520.

2 A. B. Yoruc, Ceram. Int., 2007, 33, 687-692.

3 K. Okano, S. Miyamaru, A. Kitao, H. Takano, T. Aketo, M. Toda, K. Honda and H. Ohtake, Sep. Purif. Technol., 2015, 144, 63-69.
4 Y. Lee, W. Wang, F. Lin and C. Lin, J. Formosan Med. Assoc., 2017, 116, 424-431.

5 W. Guan, F. Ji, Q. Chen, P. Yan and Q. Zhang, Ceram. Int., 2013, 39, 1385-1391.

6 R. A. Rashid, R. Shamsudin, M. H. A. Azmi and A. Jalar, Ceram. Int., 2014, 40, 6847-6853.

7 F. Panahi, S. Mahmood and R. Shidpour, Mater. Sci. Eng., C, 2017, 80, 631-641.

8 C. Xie, P. Li, Y. Liu, F. Luo and X. Xiao, Mater. Sci. Eng., C, 2016, 67, 433-439.

9 I. A. W. B. Siqueira, N. Koba, D. Moura, J. Paulo, D. B. Machado, E. Henrique, F. Roberto and E. De Sousa, Mater. Lett., 2017, 206, 210-213.

10 M. Saini, Y. Singh, P. Arora, V. Arora and K. Jain, World J. Clin. Cases, 2015, 3, 52-57.

11 S. Zeeshan, S. Corneliu and G. Michael, Materials, 2015, 8, 2953-2993.

12 L. I. Castelan-Velazco, J. Mendez-Nonell, S. Sanchez-Valdes and M. F. Ramos-deValle, Polym. Bull., 2009, 110, 99-110.

13 M. S. M. Eldin, E. A. Soliman, A. I. Hashem and T. M. Tamer, Trends Biomater. Artif. Organs, 2008, 22, 158-168.

14 S. Nazir, T. Hussain, A. Ayub, U. Rashid and A. J. Macrobert, Nanomedicine: Nanotechnology, Biology and Medicine, 2014, 10, 19-34.

15 T. Mcnally, W. R. Murphy, C. Y. Lew, R. J. Turner and G. P. Brennan, Polymer, 2003, 44, 2761-2772.

16 J. Pagacz, K. N. Raftopoulos, A. Leszczyn and K. Pielichowski, J. Therm. Anal. Calorim., 2016, 123, 1225-1237.

17 S. Venkataramani, J. H. Lee, M. G. Park and S. Ch. Kim, J. Macromol. Sci., Part A: Pure Appl. Chem., 2009, 46, 65-73.

18 X. Liu, Ch. Wang, Y. Liu, J. Chen, L. Mao, J. Yang and W. Wang, J. Macromol. Sci. Part B Phys., 2018, 57, 465-478.

19 W. E. Van Zyl, M. García, B. A. G. Schrauwen, B. J. Kooi and J. T. M. De Hosson, Macromol. Mater. Eng., 2002, 287, 106110.

20 M. Mehrali, S. F. Seyed Shirazi, S. Baradaran, M. Mehrali, H. S. C. Metselaar, N. A. Bin Kadri and N. A. A. Osman, Ultrason. Sonochem., 2014, 21, 735-742.

21 A. Meiszterics, L. Rosta, H. Peterlik, J. Rohonczy, S. Kubuki, P. Henits and K. Sinkó, J. Phys. Chem., 2010, 114, 1040310411.

22 C. Chen, C. Ho, S. Lin and S. Ding, Ceram. Int., 2015, 41, 5445-5453.

23 H. Aguiar, J. Serra, P. González and B. León, J. Non-Cryst. Solids, 2009, 355, 475-480.

24 D. A. Eurov, S. A. Grudinkin, D. A. Kurdyukov and V. G. Golubev, Phys. Solid State, 2015, 57, 2087-2092.

25 J. Abe, N. Hirano and N. Tsuchiya, J. Mater. Sci., 2012, 47, 7971-7977.

26 Y. Zhu, C. Wu, Y. Ramaswamy, E. Kockrick, P. Simon, S. Kaskel and H. Zreiqat, Microporous Mesoporous Mater., 2008, 112, 494-503.

27 C. Wu, J. Chang and W. Fan, J. Mater. Chem., 2012, 22, 16801-16809.

28 J. Zhang and Y. Zhu, Microporous Mesoporous Mater., 2014, 197, 244-251. 
29 T. Ishisue, M. Okamoto and K. Tashiro, Polymer, 2010, 51, 5585-5591.

30 I. A. Vorsina, T. F. Grigorèva, T. A. Udalova, S. V Vosmerikov and N. Z. Lyakhov, Russ. J. Appl. Chem., 2015, 88, 488-493.

31 R. M. Almeida and A. C. Marques, Characterization of sol gel materials by Infrared spectroscopy, in Handbook of SolGel Science and Technology, ed. L. Klein, M. Aparicio and A. Jitianu, Springer, Switzerland, 1st edn, 2017, pp. 1-31.
32 E. L. Papadopoulou, J. A. Heredia-Guerrero, M. I. Vázquez, J. Benavente, A. Athanassiou and I. S. Bayer, Polymer, 2017, 120, 255-263.

33 A. Abdal-hay, H. Raj Pant and J. K. Lim, Eur. Polym. J., 2013, 49, 1314-1321.

34 K. M. Lee, M. Kim, E. Lee, S. H. Baeck and S. E. Shim, Electrochim. Acta, 2016, 213, 124-131.

35 W. Ashraf and J. Olek, J. CO2 Util., 2018, 23, 61-74.

36 Heriyanto, F. Pahlevani and V. Sahajwalla, J. Cleaner Prod., 2018, 172, 3019-3027. 